Devil wears (counterfeit) Prada: A study of antecedents and outcomes of attitudes towards counterfeits of luxury brands 


\title{
Devil wears (counterfeit) Prada: A study of antecedents and outcomes of attitudes towards counterfeits of luxury brands
}

\begin{abstract}
Purpose - The paper examines how social and personality factors influence Chinese consumers' attitudes towards counterfeits of luxury brands and how these two sets of variables influence purchase intention. It provides a profile of buyers and non-buyers of counterfeits of luxury brands.
\end{abstract}

Design/methodology/approach -A self-administered questionnaire was designed using established scales. A survey was conducted in downtown Shanghai through the "mall intercept” method. A variety of statistical techniques was used to analyse the data.

Findings - Status consumption and integrity are strong influencers of purchase intention, whereas normative susceptibility, information susceptibility, personal gratification, value consciousness, novelty seeking had weaker influencing relationships. The attitude towards counterfeiting of luxury brands is found to influence purchase intention. Collectivism does not influence attitudes nor purchase intentions towards counterfeits of luxury brands.

Research limitations/implications - The findings are only limited to Chinese consumers in Shanghai, which cannot be generalized across whole of China. Further, only luxury brands are considered. Other cultural contexts and product categories should be investigated in future.

Practical implications - This research provides an in depth understanding of Chinese consumers' attitudes towards counterfeits of luxury brands. The research findings can be used to formulate strategies for academia, practitioners and more importantly policy makers to help eradicate or at the very least curb counterfeiting activities.

Originality/ value - Most studies focused on counterfeiting and piracy of music and other optical media whereas this paper focussed exclusively on luxury brands. Status consumption is also added as an antecedent towards attitudes and purchase intention of counterfeits.

\section{Keywords}

Counterfeiting, China, Chinese consumers, luxury brands 


\section{BACKGROUND \\ Counterfeiting in China}

China has been acknowledged as the number one country perpetrator of counterfeiting, where all sources of counterfeit goods can be traced (Hung, 2003; Forney, 2005; Cheung and Prendergast, 2006; Bian and Veloutsou, 2007). It has been recorded that $20 \%$ of goods sold in the Chinese market are counterfeit goods (Alcock, 2003; Bian and Veloutsou, 2007). These goods span across a wide range of products including apparels, cigarettes, electronics, food, mobile phones, pharmaceuticals, skin care products and many others (Bush et al., 1989; Jacobs et al., 2001; Trainer, 2002). In particular, as Chinese are avid luxury consumers (Wong and Ahuvia, 1998; Jiang, 2005; Sonmez and Yang, 2005; Li and Su, 2007), counterfeiting of luxury brands has reached astronomical levels.

The trading of luxury goods in China has proved to be a lucrative market as it has been noted as the world's third largest consumer of high-end fashions, accessories and other luxury products (Ernst \& Young China, 2005; Chadha, 2007; Chung, 2007). The market is recorded to generate more than $\$ 2$ billion in sales a year and is projected to continue growing (Ernst \& Young China, 2005) by an estimated of 25\% annually in the coming years (Goldman Sachs, 2005). With such a rampant counterfeit industry, it could diminish profits and attractiveness for foreign investors and may threaten the brand equity of both international and local luxury products (Chow, 2000; Trainer, 2002).

The catalytic growth of counterfeiting can be attributed to the increase in world trade and emerging new markets, fast paced technology advancements and also the increase in goods that are worth counterfeiting (Cottman, 1992; Wee et al., 1995; Bloch et. al, 1998; Counterfeiting: Tricks and trends, 2003). Luxury brands are easily counterfeited as it is easy to sell and incur low manufacturing costs (Shultz and Saporito, 1996; Gentry et al., 2006). Moreover consumer demand is also increasing due to the pursuit of status goods and the desire of being in tune with fashions and fads (Chang, 1998; Eisend and Schuchert-Güler, 2006). It is reported by Chinese officials that counterfeiting is a staggering \$16 billion business annually (Bian and Veloutsou, 2007). While there seems to be some conscious efforts to fully "stamp out" the teething problem including implementing processes to trace, detect and prosecute counterfeiting offenders (Nill and Shultz, 1996; Chow, 2000; Prendergast et al., 2002), the attempt seems futile with the increasingly sophisticated counterfeit syndicates making it harder to detect and eradicate 
these activities (Clark, 2006). There are also noted flaws and loopholes in China's copyright and intellectual property legislation that allow such activities to persist. The lack of serious penalties also allows offenders to be increasingly brazen in their illegal pursuits (Hung, 2003; Sonmez and Yang, 2005; Clark, 2006). Furthermore, if the government were to take serious measures, it would need to be on a national, provincial or local level to be effective. However, to date there are no perceived cohesive efforts to challenge this problem (Wee et al., 1995; Trainer, 2002; Bian and Veloutsou, 2007).

\section{Justification of study}

Although past research conducted have examined the supply side of counterfeiting (Ang et al., 2001; Bush et al., 1989; Albers-Miller, 1999; Alcock et al., 2003), there have also been an increasing number of studies conducted on the consumer behavioural aspect of counterfeiting (such as Bamossy and Scammon, 1985; Bloch et al., 1993; Wee et al., 1995; Cordell et al., 1996; Wilke and Zaichkowsky 1999; Gentry et al., 2000; Nia and Zaichkowsky, 2000; Gentry et al., 2001). These research have focused on price determinants (Bloch et al., 1993; Albers-Miller, 1999; Harvey and Walls, 2003); nonprice determinants such as attitudes (Wee et al., 1995; Tom et al., 1998; Ang et al., 2001; Wang et al., 2005; Cordell et al., 1996; Prendergast et al., 2002; Furnham and Valgeirsson, 2007); ownership of counterfeit luxury products (Cheung and Prendergast, 2006) and across a number of cultural contexts (Tom et al, 1998; Ang et al., 2001; Penz and Stöttinger, 2005; Yoo and Lee, 2005; Eisend and Schuchert-Güler, 2006).

This paper strives to extend the call for research to understand the behavioural intentions of the consumers who consciously seek out counterfeit brands and indulge in purchase regardless of the threat of imposed penalties (Bloch et al., 1993; Cordell et al., 1996; Prendergast et al., 2002). Findings would allow practitioners and policy makers to formulate more effective strategies to diminish the counterfeiting problem in China (Bloch et al., 1993; Ang et al., 2001). It strives to explore the Chinese consumers' mindset in relation to purchasing counterfeits of luxury brands.

The aims are of this study are therefore fourfold. First, it examines the relationship between "social and personality factors" and "attitudes towards counterfeits of luxury brands" of Chinese consumers. Building on past research, the variable of status consumption is added to better project consumption behaviour of Chinese consumers. 
Second, it investigates the relationship between consumer attitudes and purchase intention of counterfeits of luxury brands. Third, it examines the relationship between "social and personality factors" and "purchase intention towards counterfeits of luxury brands”. Lastly, it evaluates the differences between the profiles of buyers and nonbuyers of counterfeits of luxury brands.

This paper is organized into several sections beginning with a discussion on extant literature and leading to the model and hypotheses development. This is followed by a description of the research method. The discussion of the findings and analysis will next be presented. Finally, the managerial implications and limitations of the study are highlighted.

\section{RELEVANT LITERATURE AND HYPOTHESES DEVELOPMENT}

\section{Counterfeits defined}

Counterfeits are reproductions of a trademarked brand (Cordell et al., 1996), which are closely similar or identical to genuine articles, including packaging, labelling and trademarks to intentionally pass off as the original product (Kay, 1990; Ang et al., 2001; Chow, 2002). Lai and Zaichkowsky (1999) stated that counterfeiting and piracy are in essence the same, since they are both the reproduction of identical copies of authentic products. These two terms have been used interchangeably (Wee, et. al., 1995; Kwong et. al., 2003). However, piracy is mainly related to software and fixed medium content such as film and music recordings (Chow, 2000; Cheung and Prendergast, 2006). Furthermore, counterfeiting is dissimilar to other forms of Intellectual Property infringements like grey market goods. De Matos et al., (2007) have utilized scales that measured grey market products for counterfeits, which is undeniably different in characteristics and definition. Grey markets are often overruns from outsourced manufacturers that are distributed through unauthorized channels (Huang et al., 2004; Gentry et al. 2006) whereas counterfeiting involves an illegally produced copy of the original article.

Research has identified two types of consumers of counterfeit products. The first would be a victim, who unknowingly and unintentionally purchase counterfeit goods due to it being so closely similar to the genuine articles (Grossman and Shapiro, 1988; Bloch et. al., 1993; Mitchell and Papavassiliou, 1997; Tom et al., 1998). However, the second is a willing participant or consumer of counterfeit products, wherein they sought out 
counterfeit products even when they know that the products are illegal (Bloch et al., 1993; Cordell et al., 1996; Prendergast et. al., 2002).

\section{Attitudes towards counterfeiting}

Counterfeit products diminish the symbolic value of authentic luxury products and dilute the brand equity (Zhou and Hui, 2003). As counterfeits are cheaper alternatives of more expensive genuine products, there might not be a noticeable difference in perceived quality (Gentry et al. 2006), which will result in the erosion of genuine luxury brand equity (Grossman and Shapiro, 1988; Jacobs et al., 2001; Zhou and Hui, 2003). According to Tom et al. (1998), consumers are more inclined to purchase products with a fashion component attached such as is the case for luxury products. Consumers are willing to pay for the visual attributes and functions without paying for the associate quality (Grossman and Shapiro, 1988; Cordell et al., 1996). Consumers are also expected to prefer counterfeit products with a famous brand name attached that would present some meaning to the consumer (Cordell et al., 1996). This reinforces the concept that only brand names that are well known or worth counterfeiting are targeted for illegal production (Eisend and Schuchert-Güler, 2006).

Past research have examined the economic, quality and legal or ethical factors that shape and influence attitudes of consumers (Cordell et al., 1996; Ang et al., 2001; Wang et al., 2005). Ultimately, the functional benefits are important when purchasing counterfeits of luxury brands. However, much more so is the desire to own the prestige and status symbol that the trademarked brand suggests (Cordell et al., 1996; Chadha, 2007). More commonly, price is also reflective of consumer attitudes towards the value of counterfeit products. Counterfeits of luxury brands are intentionally capitalizing on the fact that their products are positioned at a lower and more competitive price (Gentry et al., 2006). On the same note, there is a compelling and addictive attraction basing on the attitudes that consumers would want to purchase a luxury branded product, but would be unwilling to foot the high price tag associated with it (Cordell et al., 1996). The general perception is that the low financial risks provide the added benefit for consumers to purchase counterfeit goods, as prices of counterfeits are relatively advantageous. In addition, because counterfeits are often at a lower price, the expectation of quality would not be equivalent to that of the genuine. As long as the basic functional requirements are met or 
the visibility and symbolic value is achieved, consumers will be satisfied (Eisend and Schuchert-Güler, 2006).

However, the product quality of counterfeit products has been improving in recent years due to better technological advancement, bringing a competitive advantage to counterfeit products (Nill and Shultz II, 1996). Certain products can be tried before purchase to gauge the functionality or performance which can encourage consumers' willingness to purchase (Cordell et al., 1996; Bian and Veloutsou, 2007). However, counterfeit products are still without warranties unlike genuine products, adding to greater financial risks of purchases (De Matos, 2007). It has been found that if the perceived product attributes between the genuine product and the counterfeit product are similar in terms of quality, the purchase intention will be higher (Wee et al., 1995; Penz and Stöttinger, 2005).

Consumers experiencing situational ethics excuse themselves for purchasing counterfeits as justifiable because they perceive themselves to be less unethical or illegal (Cordell et al., 1996; Albers-Miller, 1999; Gupta et al., 2004). Hence, consumers feel less responsible towards their role as a counterfeit patron. This double standard shows indifferent attitudes towards the consumption of counterfeit goods, since major corporations might not suffer from slight loss of profits (Cordell et al., 1996; Ang et al., 2001; De Castro et al., 2007).

Although there are different measures developed for attitudes towards the purchase of pirated software (e.g. Kwong et. al.'s (2003); Wang et. al.’s (2005)), testing consumer attitudes towards counterfeits of luxury brands is still at its infancy (e.g. Ang et al., 2001). More could be focussed on the examination of the individual's behavioural beliefs and feelings towards counterfeiting (Wee et al., 1995). Further, product attributes (such as quality, texture, status signalling, etc) of counterfeits are unlike pirated software, and are more inconsistent and more easily distinguishable.

In view of the Chinese consumers, attitudes towards counterfeits of luxury brands can be influenced by a number of antecedents. The literature largely supports two groups, namely social factors including the likes of normative and informational susceptibility towards social influence and collectivism; and personality factors such as value consciousness, integrity, personal gratification, novelty seeking and status consumption. 


\section{Antecedents - Social Factors}

Social influence refers to the effect that others have on an individual consumer's behaviour (Ang et al., 2001). Two common forms of consumer susceptibility to social influences are information susceptibility and normative susceptibility (Bearden et al., 1989; Wang et al., 2005). Information susceptibility is the basis of purchase decision on expert opinion of others (Ang et al., 2001; Wang et al., 2005). The assurance of opinion of others plays an important role as a point of reference especially when consumers have little knowledge of the product category in question. If peers or reference groups were to have expert knowledge on the differences between originals and counterfeits (such as in product quality), the negative consequences of being perceived to purchase counterfeits will therefore have an effect on consumers' perception towards counterfeits of luxury brands. Therefore, consumers would have a negative attitude towards counterfeits of luxury brands. On the other hand, normative susceptibility concerns purchase decisions that are based on the expectations of what would impress others (Ang et al., 2001; Wang et al., 2005; Penz and Stöttinger, 2005). As self-image plays a huge role, purchasing counterfeits of luxury brands does not enhance or portray a good impression. Therefore, consumer attitudes towards counterfeits of luxury brands would be unfavourable. It can be postulated that:

$\boldsymbol{H}_{1 \boldsymbol{a}}$ Normative and Information susceptibility have a negative influence on consumer attitudes towards counterfeits of luxury brands.

Although there have been past research stating that the Chinese collectivistic culture is one of the primary contributing reasons to high counterfeiting rates in China (Swinyard et. al., 1990; Marron and Steel, 2000; Husted, 2000; Wang et. al., 2005), the degree of collectivism varies depending on geographical locations. Inland Chinese are deemed to be more collectivistic than residents in the more developed coastal cities such as Guangzhou, Beijing and Shanghai (Koch and Koch, 2007). The more individualistic culture of these developed coastal cities could also be attributed to the massive presence of foreign investments.

Further, collectivism is target specific (Hui et al., 1991). It could be that certain individuals are collectivistic to certain groups of people and individualistic towards others. Hofstede (1991) has also noted that countries that are more collectivistic tend to 
have slower economic development. At the rate of China's development, it could well be a strong segregation of collectivistic consumers and increasing numbers of individualistic consumers due to greater foreign influences.

Collectivism has been discussed as one of the factors in Asian societies to positively influence consumer attitudes towards pirated products and counterfeits. It is therefore likely that Chinese consumers would have favourable attitudes towards counterfeits of luxury brands. It can be postulated that:

$\boldsymbol{H}_{1 \boldsymbol{b}}$ Collectivism has a positive influence on consumer attitudes towards counterfeits of luxury brands.

\section{Antecedents - Personality Factors}

Most purchasers of genuine luxury brands pursue value for brand, prestige and image benefits, but are unwilling to pay the high price for it (Bloch et al., 1993). For a lower price and a slightly substandard quality, it is still considered value for money (Bloch et al., 1993; Lichtenstein et al., 1990; Ang et al., 2001; Wang et al., 2005). As counterfeits of luxury brands usually provide the same functional benefits as the original, but at a fraction of the price of the genuine product, it is perceived favourably. For consumers who are value conscious, they would have positive attitudes towards counterfeits of luxury brands. It can be postulated that:

$\boldsymbol{H}_{1 c}$ Value consciousness has a positive influence on consumer attitudes towards counterfeits of luxury brands

In accordance to Kohlberg's (1976) moral competence theory, consumer behaviours are affected by their personal sense of justice. The influence of basic values like integrity will affect the judgement towards succumbing to unethical activities (Steenhaut and van Kenhove, 2006). Integrity is determined by personal ethical standards and obedience towards law. If consumers view integrity as crucial, the chances of them viewing counterfeits of luxury brands in a positive light would be much smaller (Ang et al, 2001; Wang et al. 2005). It can be postulated that:

$\boldsymbol{H}_{1 \boldsymbol{d}}$ Novelty seeking has a positive influence on consumer attitudes towards counterfeits of luxury brands

Personal gratification is the need for a sense of accomplishment, social recognition, and the desire to enjoy the finer things in life (Ang et al., 2001; Wang et al., 2005). 
Consumers with high sense of personal gratification would be more conscious of the appearance and visibility of fashion products. They are probably less prone to accept goods of slightly inferior quality. Consumers with a high sense of personal gratification will value the genuine versions of luxury products hence they will have a negative attitude towards counterfeits of luxury brands. It can be postulated that:

$\boldsymbol{H}_{1 \boldsymbol{e}}$ Integrity has a negative influence on consumer attitudes towards counterfeits of luxury brands

Novelty seeking is the curiosity of individuals to seek variety and difference (Hawkins et al., 1980; Wang et al., 2005). A consumer who is inclined to try new products would probably have positive attitudes towards counterfeits of luxury brands. Novelty seeking consumers are particularly inclined towards products with low purchase risk. Hence the low cost of counterfeit products are well suited to satisfying their curiosity and the need for experimentation (Wee et al., 1995). It can be postulated that:

$\boldsymbol{H}_{1 f}$ Personal gratification has a negative influence on consumer attitudes towards counterfeits of luxury brands

Status consumption has long been defined as the purchase, use, display and consumption of goods and services as a means of gaining status (Veblen, 1899, 1953; Packard, 1959; Mason, 1981; Scitovsky, 1992; Eastman et al., 1997). Status commands respect, consideration and envy from others and represents the goals of a culture (Csikszentmihalyi and Rochberf-Halton, 1981, pg. 29). Furthermore, it involves a social ranking or recognition that a group would award to an individual (Packard, 1959; Dawson and Cavell, 1986; Scitovsky, 1992; Eastman et. al., 1997), that is irrespective of social and income level. It is inaccurate to assume that only the wealthy are prone to status consumption (Freedman, 1991; Miller 1991; Eastman et al., 1997; Shipman, 2004). Status consumption is for consumers who are both seeking self-satisfaction as well as for the show to surrounding others usually through visible evidence (Eastman et al., 1997). Status consumers seek to possess brands that exude brand symbols that reflect their selfidentity posts numerous implications for their attitudes towards counterfeits of luxury brands (Hoe et al., 2003). Hence, the addition of status consumption construct using a developed scale from Eastman et al. (1997) could well measure whether consumers who are more status conscious would be attracted to counterfeit luxury products. As status consumers are more conscious of the display of accomplishment, their attitudes towards 
counterfeits of luxury brands would be unfavourable. In the case of Chinese consumers, many have newfound wealth and would be anxious to display their wealth to gain the impression of success, wealth and accomplishment (Shipman, 2004). Furthermore, the importance of 'face' to the Chinese accentuates the proneness to succumbing to status consumption ( $\mathrm{Li}$ and $\mathrm{Su}, 2006)$. It can be postulated that:

$\boldsymbol{H}_{1 \boldsymbol{g}}$ Status consumption has a negative influence on consumer attitudes towards counterfeits of luxury brands

\section{Purchase Intention - Theory of Planned Behaviour}

According to the theory of planned behaviour (TPB), the purchase behaviour is determined by the purchase intention, which is in turn determined by attitudes Fishbein and Ajzen, 1975. Attitudes towards behaviour instead of towards the product are noted to be a better predictor of behaviour (Fishbein, 1967; Fishbein and Ajzen, 1975; Lutz, 1975; Yi, 1990; Penz and Stöttinger, 2005). However, the theory also stated that the opportunities and resources such as the accessibility of counterfeit products must be present before purchase behaviour can be performed. Without such circumstances, regardless of how favourable intentions are, it would be difficult to perform purchase (Chang, 1998).

Unethical decision making such as purchasing of counterfeits is explained largely by the attitudes, regardless of product class (Wee et al., 1995; Chang, 1998; Ang et al., 2001). The more favourable consumer attitudes towards counterfeiting are, the higher the chances that they will purchase counterfeit brands. Similarly, the more unfavourable consumer attitudes towards counterfeiting are, the less likely are the chances of purchase (Wee et al., 1995). It is therefore postulated that:

$\boldsymbol{H}_{2}$ There is a significant relationship between attitude and purchase intention towards counterfeits of luxury brands

In addition, social and personality antecedents have long been established to have an influence on consumer decision making (Miniard and Cohen, 1983) towards purchase intention. It is therefore postulated that:

$\boldsymbol{H}_{3}$ There is a significant relationship between social and personality factors (information susceptibility, normative susceptibility, collectivism, value consciousness, novelty seeking, integrity, personal gratification and status 
consumption) and purchase intention towards counterfeits of luxury brands.

\section{Buyers and non-buyers of counterfeits of luxury brands}

Past research have shown that buyers and non-buyers of counterfeits of luxury brands hold different attitudes towards counterfeits of luxury brands (Ang et al., 2001; Wang et al., 2005). Buyers of counterfeits of luxury brands will perceive their actions in a more favourable light, and are also known to have some degree of loyalty towards counterfeit goods (Tom et al., 1998). As such, the following hypothesis is presented:

$\boldsymbol{H}_{4}$ Buyers of counterfeits of luxury brands have more positive attitudes towards counterfeits of luxury brands than non-buyers.

The above hypotheses are presented in the following model:

\section{Insert Fig. 1 Here}




\section{METHODOLOGY}

\section{Data collection}

Data were collected via a mall intercept at a major shopping complex in the city of Shanghai, greater China. Shoppers were approached to participate in a self-administered questionnaire. Every fifth individual that crossed a designated spot outside the main entrance of the mall was approached to participate. Prior to the data collection, interviewers were being trained and instructed on how to administrate the survey instrument and to include respondents with different demographic profiles. The data collection was conducted over a two week period on both weekdays and weekend, out of which $14 \%$ of the shoppers agreed to take part in the survey. Measuring consumers' attitudes and perceptions in a mall or shopping related environment would allow population of interest to relate to what the research intends to measure, which in this case are attitudes and consumer purchase intention (Cowan, 1989; Hornik and Ellis, 1988). This is an improvement on ecological validity as most previous research focused on student samples (Wang et al., 2005; Nia and Zaichkowsky, 2000).

\section{Survey Instrument}

The survey instrument was developed in English and translated into Chinese by a professional native speaker. It was then back translated and checked for inconsistencies by another professional translator. The five sections consisted of established scales and demographics. The description of scale items and their reliabilities are reflected in Table 1. Sections A and B measured social factors and personality factors. Section C examines attitudes and purchase intentions towards counterfeits of luxury brands. Section D comprised of items regarding purchasing habits of counterfeit products and brands. Two additional items, "I will buy counterfeits of luxury brands from peddlers" and "I will buy counterfeits of luxury brands" were added to the scale to better capture consumers purchase intentions of counterfeits. Section E comprised of demographic information of respondents. All items were measured on a seven point Likert scale with 1 representing “strongly disagree” and 7 representing “strongly agree”.

\section{Insert Table 1 Here}




\section{FINDINGS AND DISCUSSION}

\section{Samples}

270 questionnaires were collected. Out of which, 68 responses were discarded due to incompletion or if respondents were not Chinese nationals. The remaining 202 usable responses were analysed with SPSS software version 14. The sample distribution between buyers and non-buyers is shown in Table 2. 58.4\% of the respondents were male. The percentage of buyers was higher than non-buyers, which is representative of high counterfeiting rates in China (Traphagan and Griffith, 1998; Wang et. al., 2005).

According to Table 2, 74.2\% of buyers were 21-35 years old. There were more nonbuyers (15.7\%) that were under 36-45 in comparison to buyers (13.9\%). Furthermore, most of the buyers and non-buyers involved in business administrative work were represented by $28 \%$ and $24.3 \%$ respectively. There were more non-buyers (14\%) who are self employed than buyers (11.5\%). The majority of buyers and non-buyers were reported to earn under RMB 50,000 (equivalent to USD 6,732.19) per annum. There were more buyers (29.5\%) who earn RMB 50,000 - 100,000 (equivalent to USD 6,732.19 -USD $13,464.39)$ than non-buyers (22\%). On the other hand, more non-buyers (14\%) were reported to earn RMB 100,001 - 150,000 (equivalent to USD 13,464.52 - USD 20,196.58) than buyers (3.4\%). The majority of respondents were reported to have a bachelor degree. However, more non-buyers (60\%) were reported to hold a bachelor degree in comparison to buyers (56.5\%). On the other hand, more buyers (10.2\%) than non-buyers (6\%) were reported to be postgraduates.

\section{Insert Table 2 Here}

\section{Attitudes towards counterfeits of luxury brands}

An exploratory factor analysis was conducted on the original 10-item attitudes towards counterfeits of luxury brands scale. Through varimax rotation, two factors emerged and were named "perceptions of counterfeits” and “social consequences”. In total, they were reduced to 7 items with an acceptable range of reliabilities as reflected in Table 3 . The scale of attitudes towards counterfeits of luxury brands is clearly two-dimensional. As such, these two factors were used independently for all subsequent regression analysis.

Insert Table 3 Here

Influence of social and personality factors on "Perceptions of counterfeits" 
Stepwise regression was conducted between "personality and social factors" and the factor of "perceptions of counterfeits" to test $H_{1 a}$ to $H_{1 g}$. The results in Table 4 show that there is a positive relationship between status consumption and "perceptions of counterfeits” ( $ß=0.601$, adjusted $R^{2}=0.283$ ). The other significant factors include novelty seeking, normative susceptibility and information susceptibility, which has a cumulative adjusted $\mathrm{R}^{2}$ of 0.367 .

While status consumption has a significant relationship with "perceptions of counterfeits", it is postulated that status consumption has a negative influence. As such, $H_{1 g}$ is rejected. In a similar vein, novelty seeking was postulated as a positive influence while the results showed otherwise. As such, $H_{1 d}$ is also rejected.

Information susceptibility emerged to have a significant negative relationship towards "perceptions of counterfeits" while normative susceptibility showed a significant positive relationship towards "perceptions of counterfeits". Hence $H_{1 a}$ is partially supported. Collectivism, value consciousness, integrity and personal gratification did not show any significant relationship hence $H_{1 b}, H_{1 c}, H_{1 e}$ and $H_{1 f}$ are rejected.

\section{Influence of social and personality factors on "Social consequences"}

Stepwise regression was conducted between "personality and social factors" and the factor "social consequences" to test $H_{1 a}$ to $H_{1 g}$. Based on the results in Table 4, integrity is the most significant factor with an adjusted $\mathrm{R}^{2}$ of 0.263 . The other significant factors are personal gratification, status consumption and value consciousness which has a cumulative adjusted $\mathrm{R}^{2}$ of 0.376 .

While value consciousness has a significant negative relationship with "social consequences", it is postulated that value consciousness a negative influence. Hence $H_{1 c}$ is rejected. Integrity, personal gratification and status consumption showed significant negative relationships towards "social consequences", therefore supporting $H_{1 e}, H_{1 f}$ and $H_{1 g}$.

From the below, collectivism, normative and information susceptibility, and novelty seeking have no significant relationship with “social consequences”, thus $H_{1 a}, H_{1 b}$ and $H_{1 d}$ are rejected. 


\section{Insert Table 4 Here}

\section{Relationship between attitudes towards counterfeits of luxury brands and purchase intention}

Regression analysis was conducted between the two factors of attitudes and purchase intention towards counterfeits of luxury brands. Both factors are significant with "perceptions of counterfeits" accounting for an $\mathrm{R}^{2}$ of $0.740(\mathrm{p}<0.000, \beta=0.861)$ followed by "social consequences" accounting for an $\mathrm{R}^{2}$ of $0.024(\mathrm{p}<0.025, \beta=-0.085)$. It seems to show that consumers' perceptions of counterfeits lead to a more positive purchase intention. However, attitudes towards "social consequences" of purchasing counterfeits of luxury brands seem to deter consumers from purchase intention, although the relationship is relatively weak. These findings are therefore in support of $\mathrm{H}_{2}$.

\section{Influence of social and personality factors on purchase intention}

Stepwise regression is conducted between social and personality factors and purchase intention of counterfeits of luxury brands. As reflected in Table 5, status consumption, integrity, value consciousness, normative susceptibility and information susceptibility emerged to have significant relationships with purchase intention.

Status consumption is shown to be the most significant factor $\left(\mathrm{p}<0.000, \beta=0.448, \mathrm{R}^{2}=\right.$ 0.325), this reflects that status consumers are also most likely to purchase counterfeits of luxury brands. Consumers who were rated highly on value consciousness $(p<0.011$, $\beta=0.203)$ and normative susceptibility $(p<0.001, \beta=0.341)$ have higher intentions to purchase. However, consumers who were rated highly on information susceptibility $(p<0.003, \beta=-0.240)$ and integrity $(p<0.003, \beta=-0.242)$ have lower intentions to purchase.

There is no significant relationship between personal gratification, collectivism and novelty seeking and purchase intention. As such, H3 is partially supported.

\section{Insert Table 5 Here}

\section{Differences between buyers and non-buyers of counterfeits of luxury brands}

Buyers and non-buyers show different attitudes towards perceptions of counterfeits. In summary, buyers perceive counterfeits of luxury brands to have similar quality $(\chi=4.07$ 
and 3.86), provide similar functions $(\chi=4.46$ and 4.27) and are as reliable $(\chi=3.83$ and 3.80) as the originals as compared to non-buyers. $H_{4}$ is accepted for the factor of "perceptions of counterfeits".

As for factor "social consequences" of attitudes towards counterfeits of luxury brands, the result shows that there is no significant difference between buyers and non-buyers. Both types of consumers hold attitudes that counterfeits infringe intellectual property, damages the interests and rights of legitimate and original manufacturers, hurt the luxury goods industry and is illegal.

\section{Insert Table 6 Here}

\section{DISCUSSION AND IMPLICATIONS}

Normative susceptibility is shown to influence consumer perceptions of counterfeits and purchase intentions. Consumers may possess the desire to own luxury brands to impress others. However, due to hefty prices of originals, consumers can only resort to counterfeits. Luxury brand companies can offer greater affordability to consumers through brand extensions and special licensed products (Wee et al., 1995). If prices could be lower and made more affordable to Chinese consumers, there might be less inclination for them to purchase to counterfeits and instead purchase the originals. It is disturbing that consumers are unable to discern between the originals and the counterfeits. Therefore, it is important for luxury firms and advertisers have to ensure that there is a differentiation between originals in terms of quality, functionality and reliability. However, brand owners need to be cautioned that this may carry the risk of eroding prestige and exclusivity for consumers who pursue the brand value that premium luxury products exude (Wee et al., 1995; Chaudhuri and Majumdar, 2006). If properly executed, there are successful cases of brand extensions such as Armani-Exchange and Miu Miu that have further accentuated the parent brand.

In terms of information susceptibility, it is also shown that consumers who rely on the expert opinion of others to purchase products would be less inclined to purchase counterfeits of luxury brands. As such, the policy makers of relevant governmental bodies should educate consumers about the negative impacts, such as counterfeits are without quality and safety assurances. Certain forms of endorsement such as celebrities and government officials would project credibility. 
It is interesting to note that in contrast to previous studies (Ang et al., 2001; Wang et al., 2005), collectivism did not play a role in influencing consumer attitudes and purchase intention towards counterfeits of luxury brands. This could be attributed to the fact that Shanghai is increasingly becoming more and more cosmopolitan with strong Western influences. This may have encouraged a certain degree of individualism ( $\mathrm{Li}$ and $\mathrm{Su}$, 2007). In such a case, advertising initiatives should focus more on the individual self rather than the collectivistic self. However, this result has to be taken with some caution, as it does not represent the whole of China.

The findings have also shown that value conscious consumers are more likely to purchase counterfeits of luxury brands. One way to combat this behaviour is to use repetition of advertising messages such as "the best clone would not be close to an original" to reinforce the quality and value of the original brand (Wee et al., 1995). These are offerings that counterfeit products are unable to imitate. For certain luxury product categories, lifetime warranties could ascertain the utmost best quality that the brand offers, adding value to the consumer's purchase. The original luxury brand manufacturers can widen the gap between risks of purchasing a low quality, fault ridden counterfeit with a sound and valuable original (Cordell et al., 1996). Loyal or current consumers can be encouraged to purchase original brands through promotional campaigns that aim at reinforcing positive attitudes towards the brand (Cheung and Prendergast, 2006).

Integrity is found to be an extremely important factor in influencing social consequences of consumer attitudes towards counterfeits of luxury brands. This reflects similar results from previous research (such as Ang et al., 2001; Wang et al., 2005). As such, from the social policy point of view the emphasis on educating consumers on ethics and morals cannot be taken lightly. Educational programs should not only be limited to schools, but also to employees of multinational companies, tourism related businesses and other domestic businesses (Simone, 2006). It has to start at the grass root level, especially during the age when learning is still developing at a faster rate. From a managerial perspective, as suggested by other studies (Wee et al., 1995; Tom et al., 1998; Ang et al., 2001; Wang et al., 2005), by putting a more 'human face' on the influences of would gain more empathy from consumers. This can be introduced through counterfeiting 
advertisements showing negative economic impacts and potential unemployment as longterm repercussions of counterfeiting activities.

It is important to note that the counterfeiting problem does not only lie with the manufacturers but also with the purchasers of counterfeits (Bloch et al., 1993). The integrity of consumers towards counterfeits of luxury brands may be diminished by the perception that luxury brand manufacturers are profiting excessively from the exorbitant prices of such goods (Penz and Stöttinger, 2005). As such, consumers justify their purchase by a self-fulfilling prophecy that they are doing no wrong. Companies of luxury brands should considered building an image of strong ethical values and social responsibility to win consumers over.

Status consumption seems to consistently influence both "perceptions of counterfeits" and "social consequences" from the measure of attitudes towards counterfeits of luxury brands. But it is interesting to note that status seeking consumers are more likely to have positive attitudes towards counterfeits of luxury brands. The only explanation could be that many Chinese consumers are becoming wealthier and the conscious need to display such wealth is higher. However, the gap between the rich and the poor is widening as a result of strong economic growth in China and the region (Chadha, 2007). For some, the desire for luxury brands is not achieved due to the lack of affordability to exorbitant price tags of original luxury brands. This contributes to a dissonance whereby consumers resort to counterfeits to satisfy their status seeking needs.

Similarly, the results reflect that status consumption influences purchase intention of counterfeits of luxury brands. Luxury brand owners should emphasize the prestige and status symbol that the brand connotes. One of the important aspects to dissuade counterfeiting would be to emphasize on the concepts of face or "mianzi" that the Chinese consumers value (Zhou and Belk, 2004). The consequences of being caught consuming counterfeits would be embarrassment and humiliation. This would probably be a strong deterrence against purchasing counterfeits (Wee et al., 1995; Zhou and Belk, 2004; Cheung and Prendergast, 2006).

One of the issues much debated in the past is the difference in perceptions in quality, reliability and functionality between counterfeit and original brands (Eisend and 
Schuchert-Güler, 2006). Admittedly, counterfeits of luxury brands in China are of unexpectedly high quality, whereby there are even "grading systems" attached to them to segregate the better quality counterfeits from the less superior ones (Gentry et al., 2006). Moreover, that is a bigger incentive for consumers to purchase a counterfeit since prices are lower and yet attributes of the original version are compatible (Wee et al., 1995). As such, the major cue for companies is to take into consideration, designing or investing in stronger differentiating product attributes and other innovations that are hard to imitate and costly to counterfeit. It would probably be easier for consumers to differentiate between original products and counterfeits (Gentry et al., 2006). This would better enforce the belief that companies do invest to improve products for consumer benefits, instead of producing relatively uninspiring products, but charging exorbitant prices. In most cases, consumers might be deceived into believing they are purchasing original articles when they are really counterfeits. Educating consumers on differentiating original items from counterfeits by providing a list of authorized retailers is very important (Gentry et al., 2006). Even though many manufacturers are afraid that this might bring more negative attention that benefit counterfeiters (Wee et al., 1995), it would be an inevitable move for a long-term success.

Other social policy initiatives could be implemented. It is regrettable that buyers and nonbuyers share the same sentiments towards the social and ethical issues pertaining to counterfeits, such as the infringement of intellectual property rights. There is only a weak relationship to not purchase counterfeits. Although instilling fear towards penalty and criminal punishments attached to counterfeiting is useful, other dimensions to change consumer behaviour may also be explored. The Chinese government should enforce a policy whereby buyers and sellers should both be prosecuted for buying or selling counterfeits. Such strategies should be in place to discourage the 'demand' and 'supply' side of counterfeiting as both parties should be held responsible (Bloch et al., 1993).

\section{CONCLUDING COMMENTS}

In summary, it is evident that consumer attitudes towards counterfeits of luxury brands play an important role in influencing consumer purchase intention. Consumers are more influenced by the perceptions of counterfeits of luxury brands than by the ethical and legal considerations. 'Integrity’ and ‘status consumption' are the most significant factors influencing attitudes and purchase intention of consumers. 
It is noted that buyers hold more positive views of counterfeits in terms of quality, reliability and functionality of counterfeits than non-buyers, which are consistent with previous research (such as, Wee et al., 1995; Nia and Zaichkowsky, 2000; Ang et al., 2001; Wang et al., 2005). Results are also consistent with prior findings by Wang et al. (2005), that there is no significant relationship in buyer and non-buyer attitudes when evaluating social consequences of counterfeiting.

There are a number of limitations worthy of improvement and future research. The study was conducted using mall intercept method, which may limit the populations that could be reached. Those who may purchase may not be regular shoppers at a shopping mall but may be in wholesale markets where counterfeit products are largely sold. As the study is a snapshot of the Chinese consumers in the coastal areas of the newly rich, extensions to populations of other areas in China of different socioeconomic groups and to other countries may produce different results. The addition of materialism and 'face consumption' constructs can be further investigated to test for their influences on Chinese consumers.

Another possibility is to focus on foreigners who travel or reside in China as buyers of counterfeit luxury brands. The examination of situational factors and mood states such as tourists on holiday, may have different results as they are likely to experience the sense of excitement softening the ethical stance. Further exploration using qualitative approaches to examine consumer purchase behaviour of counterfeit products may provide deeper insights. While this study reflects that the integrity of consumers plays a role in influencing purchase intention, it might differ in other product categories such as pirated CDs and software. Actual ownership can be measured to determine if buyers are also owners of counterfeit products. 


\section{References}

Albers-Miller, N. D. 1999, “Consumer misbehaviour: why people buy illicit goods”, Journal of Consumer Marketing, Vol. 16, Iss. 3, pp. 273 - 287.

Alcock L., Chen, P., Ch'ng, H.M. and Hodson S. 2003, "Counterfeiting: tricks and trends”, Brand Management Vol.11, Iss.2, pp.133-136.

Ang, S. H., Cheng, P. S., Lim, E. A. C. and Tambyah, S. K. 2001, "Spot the difference: consumer responses towards counterfeits", Journal of Consumer Marketing, Vol. 18, Iss. 3, pp. $219-235$.

Ajzen, I., 1991. The theory of planned behavior. Organizational Behavior and Human Decision Processes 50, 179-211.

Bamossy, G. 2002. “Truth or Myth? Commercializing the 'Authentic' Vincent Van Gogh”, Advances in Consumer Research, Vol. 29, pp. 44 - 45.

Bearden, W. O., Netemeyer, R. G. and Teel, J. E. 1989, "Measurement of Consumer Susceptibility to Interpersonal Influence", Journal of Consumer Research, Vol. 15, Iss. 4, pp. $473-481$.

Bian, X. and Veloutsou, C. 2007, “Consumers' attitudes regarding non-deceptive counterfeit brands in the UK and China”, Brand Management, Vol. 14, Iss. 3, pp. 211-222. Retrieved from Business Source Premier Database.

Bloch, P. H., Bush, R. F. and Campbell, L. 1993, “Consumer “Accomplices” in Product Counterfeiting: A Demand-Side Investigation”, Journal of Consumer Marketing, Vol. 10, Iss. 2, pp. $27-36$.

Bush, R. F., Bloch, P. H. and Dawson, S. 1989, "Remedies for Product Counterfeiting", Business Horizons, Vol. 32, Iss. 1, pp. 59-65.

Chadha, R. 2007, “From Mao suits to Armani”, Advertising Age, Vol. 78, Iss. 2, p.27.

Chang, M. K. 1998, "Predicting Unethical Behaviour: A Comparison of the Theory of Reasoned Action and the Theory of Planned Behaviour”, Journal of Business Ethics, Vol. 17, pp. $1825-1834$.

Chaudhuri, H. R. and Majumdar, S. 2006, "Of Diamonds and Desires: Understanding Conspicuous Consumption from a Contemporary Marketing Perspective, Academy of Marketing Science Review, Vol. 2006, Iss. 11.

Cheung, W. L. and Prendergast, G. 2006, “Buyers' perceptions of pirated products in China”, Marketing Intelligence \& Planning, Vol. 24, Iss. 5, pp. 446 - 462.

"China to be top consumer of luxury brands: Goldman Sachs" 2005. Embassy of the People's Republic of China in the United States of America. 
Chow, D.C.K. 2000, "Enforcement Against Counterfeiting in the People’s Republic of China”, Northwestern Journal of International Law \& Business, Vol. 20, Iss. 3, p. 447.

Clark, D 2006, “Counterfeiting in China: A Blueprint for Change”, The China Business Review, Iss. Jan - Feb, p. 14.

Cordell, V. V., Wongtada, N. and Kieschnick Jr., R. L. 1996, "Counterfeit Purchase Intentions: Role of Lawfulness Attitudes and Product Traits as Determinants", Journal of Business Research, Vol. 35, pp. 41 - 53.

Counterfeiting: Tricks and trends 2003, Brand Management, Vol. 11, Iss. 2, pp. 133 136.

Cowan, C. D. 1989, "Mall Intercepts and Clinical Trials: The Philosophy of Inference From Different Types of Research Designs”, Marketing Research, Vol.1, Iss. 1, pp. $15-22$.

Csikszentmihalyi, M. and Rochberg-Halton, E. 1981, The meaning of things: Domestic symbols and the self. New York: Cambridge University Press

Dawson, S. and Cavell, J. 1986, Status recognition in the 1980's: Invidious distinction revisited, in Wallendorf, M. and Anderson, P. (eds.), Advances in Consumer Research, Vol. 14, pp. 487 - 491. Association for Consumer Research: Provo, UT.

De Castro, J. O., Balkin, D.B. and Shepherd, D. A. 2007, “Knock-off or Knockout?”, Business Strategy Review, Spring, pp. 28 - 32.

De Matos, C. A., Ituassu, C. T. and Rossi, C. A. V. 2007, “Consumer attitudes toward counterfeits: a review and extension”, Journal of Consumer Marketing, Vol. 24, Iss. 1, pp. 36-47.

Eastman, J. K., Fredenberger, B., Campbell, D. and Calvert, S. 1997, “The Relationship Between Status Consumption and Materialism: A Cross-cultural Comparison of Chinese, Mexican, and American Students”, Journal of Marketing Theory and Practice, Iss. Winter.

Eisend, M. and Schuchert-Güler, P. 2006, "Explaining Counterfeit Purchases: A Review and Preview”, Academy of Marketing Science Review, Vol. 2006, Iss. 12.

Ernst \& Young China 2005, China: The New Lap of Luxury, Global Retail and Consumer Products in Ernst \& Young China.

Fishbein, M. 1967, Readings in attitude theory and measurement, New York: Wiley.

Fishbein, M. and Ajzen, I. 1975, Belief, Attitude, Intention, and Behaviour: An Introduction to Theory of Research, Addison Wesley, Reading.

Forney, M. 2005, "Faking It", Time. Retrieved from http://www.time.com/time/magazine/article/0,9171,501050613-1069142,00.html on 9 June, 2007. 
Freedman, A.M. 1991, "Little Wishes Form the Big Dream: The American Way of Buying”, Wall Street Journal, pp. 4 - 10.

Frost-Norton, T. 2005. "The future of mall research: Current trends affecting the future of marketing research in malls”, Journal of Consumer Behaviour, Vol. 4, Iss. 4, pp.293-301

Furnham, A. and Valgeirsson, H. 2007, "The effect of life values and materialism on buying counterfeit products”, The Journal of Socio-Economics, Vol.

Gentry, J.W., Putrevu, S., Shultz II, C. and Commuri, S. 2001. How Now Ralph Lauren? The Separation of Brand and Product in a Counterfeit Culture, Advances in Consumer Research, Vol. 28, Iss. 1, pp. 258 - 265.

Gentry, J. W., Putrevu, S. and Shultz II, C. J. 2006, “The effects of counterfeiting on consumer search”, Journal of Consumer Behaviour, Vol. 5, Iss. 3, pp. 245 - 256.

Gordon, P. 2002, “Keeping Pace with Counterfeiters”, The Journal of World Intellectual Property, Vol. 5, Iss. 6, pp. 965 - 979.

Grossman, G. M. and Shapiro, C. 1988, "Foreign counterfeiting of status goods", Quarterly Journal of Economics, February, pp. 79 - 100.

Gupta, P.B., Gould, S. J. and Pola, B. 2004, “’'To Pirate or Not to Pirate”: A Comparative Study of the Ethical Versus Other Influences on the Consumer's Software Acquisition-Mode Decision”, Journal of Business Ethics, Vol. 55, pp. 255 - 274.

Harvey, P. J. and Walls, W. D. 2003, "Laboratory Markets in Counterfeit Goods: Hong Kong Versus Las Vegas”, Applied Economic Letters, Vol. 10, pp. 883 - 937.

Hawkins, D. I., Coney, K. A. and Best, R. J. 1980, Consumer Behaviour: Implications for Marketing Strategy, Business Publications, Dallas, TX.

Hoe, L., Hogg, G., and Hart, S. 2003, “Fakin' It: Counterfeiting and Consumer Contradictions", In European Advances in Consumer Research 6 ed., Turley, D. and Brown, S. Provo, UT: Association for Consumer Research, pp. 60 - 67.

Hofstede, G. 1991. Cultures and organizations: Software of the mind. London: McGraw Hill.

Hornik, J. and Ellis, S. 1988, "Strategies to Secure Compliance for a Mall Intercept Interview”, Public Opinion Quarterly, Vol. 52, Iss. 4, pp. 539 - 551.

Huang, J.H., Lee, B. C.Y., Ho, S. H. 2004. "Consumer attitude toward gray market goods”, International Marketing Review, Vol. 21, No. 6, pp. 598 - 614.

Hung, C. L. 2003, "The Business of Product Counterfeiting in China and the Post-WTO Membership Environment”, Asia Pacific Business Review, Vol. 10, Iss. 1, pp. 58 77. 
Hui, C. H., Triandis, H. C., and Yee, C. 1991. "Cultural differences in reward allocation: Is collectivism the explanation?”, British Journal of Social Psychology, Vol.30, pp.145-157.

Husted, B. W. 2000, “The impact of national culture on software piracy", Journal of Business Ethics, Vol. 26, Iss. 3, pp. 197 - 211.

Jacobs, L, Samli, A. C. and Jedlik, T. 2001. "The Nightmare of International Product Piracy: Exploring Defensive Strategies”, Industrial Marketing Management, Vol. 30, pp. $499-509$.

Jiang, J. 2005, “Time to luxuriate in luxury products”, China Daily, 15 September, p. 11.

Kassarjian, H.H. 1971, "Personality and consumer behaviour: A review”, Journal of Marketing Research, Vol. 8, Iss. 000004.

Kay, H. 1990, “Fake’s progress”, Management Today, July, pp. 54 - 58.

Kaynama, S. A. and Smith, L. W. 1994, “ Predicting buying behaviour from buying intent”, Journal of Strategic Marketing, Vol. 2, pp. 281 - 291.

Koch, J. B. and Koch, P. T. 2007, "Collectivism, individualism, and outgroup cooperation in a segmented China”, Asia Pacific Journal of Management, Vol. 24.

Kohlberg, L. 1976. "Moral Stages and Moralization: The Cognitive Development Approach, in Moral Development and Behavior: Theory, Research and Social Issues. Lickona, T., ed. Holt, Rinehart, and Winston: New York, pp. 31 - 53.

Kwong, K. K., Yau, O. H. M., Lee, J. S. Y., Sin, L. Y. M., and Tse, A. C. B. 2003, “The Effects of Attitudinal and Demographic Factors on Intention to Buy Pirated CDs: The Case of Chinese Consumers”, Journal of Business Ethics, Vol. 47, Iss. 3, pp. $223-235$.

Lai, K. K. Y. and Zaichkowsky, J. L. 1999, "Brand imitation: do the Chinese have different views?”, Asia Pacific Journal of Management, Vol. 16, Iss. 2, pp. 179 192.

Li, J. J. and Su, C. 2007, "How face influences consumption: A comparative study of American and Chinese consumers”, International Journal of Market Research, Vol. 49, Iss. 2, pp. $237-250$.

Lichtenstein, D.R., Netemeyer, R.G. and Burton, S. 1990, "Distinguishing coupon proneness from value consciousness: An acquisition-transaction utility theory perspective”, Journal of Marketing, Vol. 54, Iss. 3., pp. 54 - 67.

Lutz, R. J. 1975, "Changing brand attitudes through modification of cognitive structure”, Journal of Consumer Research, Vol. 1, pp. 49 - 59.

Mah, A. 2006, "Fakes still have their niche in China”, International Herald Tribune. Retrieved from http://www.iht.com/articles/2006/03/05/opinion/rfake.php. 
Miller, C. 1991, “Luxury Goods Still Have Strong Market Despite New Tax”, Marketing News, Vol. 25, pp. $1-7$.

Marron, D. B. and Steel, D. G. 2000, "Which countries protect intellectual property? The case of software piracy”, Economic Inquiry, Vol. 38, Iss. 2, pp. $159-174$.

Mason, R.S. 1981, Conspicuous Consumption: A Study of Exceptional Consumer Behavior. New York: St. Martin’s Press.

Miniard, P.W. and Cohen, J.B. 1983, "Modeling Personal and Normative Influences on Behavior", Journal of Consumer Research, Vo. 10, Iss. 2.

Mitchell, V. W. and Papavassiliiou, V. 1997, "Exploring consumer confusion in the watch market”, Marketing Intelligence \& Planning, Vol. 15, Iss. 4, pp. 164 - 172.

Nia, A. and Zaichkowsky, J.L. 2000, "Do counterfeits devalue the ownership of luxury brands?”, The Journal of Product and Brand Management, Vol. 9, Iss. 7.

Nill, A. and Shultz II, C. J. 1996, “The Scourge of Global Counterfeiting”, Business Horizons, Vol. 39, Iss. 6, pp. $37-43$.

Packard, V. 1959, The Status Seekers, New York: Simon and Schuster.

Penz, E. and Stöttinger, B. 2005, "Forget the "Real" Thing - Take the Copy! An Explanatory Model for the Volitional Purchase of Counterfeit Products”, Advances in Consumer Research, Vol. 32, pp. 568 - 575.

Prendergast, G., Chuen, L. H. and Phau, I. 2002, "Understanding consumer demand for non-deceptive pirated brands”, Marketing Intelligence \& Planning, Vol. 20, Iss. 7, pp. $405-416$.

Rokeach, M. 1973, The Nature of Human Values. New York: Free Press

Scitovsky, T. 1992, The Joyless Economy: The Psychology of Human Satisfaction, revised edn, Oxford, Oxford University Press

Shipman, A. 2004, "Lauding the Leisure Class: Symbolic Content and Conspicuous Consumption”, Review of Social Economy, Vol.62, Iss. 3, pp. 277 - 289.

Shultz C.J. II, and Soporito, B. 1996, "Protecting intellectual property strategies and recommendations to deter counterfeiting and brand piracy in global markets:, Columbia Journal of World Business, Vol. 31, Iss. Spring, pp. 18 - 28.

Simone Jr., J. T. 2006, "Silk Market Fakes - Light at the End of the Tunnel: A new strategy holds promise for fighting fakes”, The China Business Review, pp. 16 - 17, $44-46$.

Sindico, D. 1999. "Trade-Mark Protection and Counterfeiting: The Kappa Group Experience”, The Journal of World Intellectual Property, Vol. 2, Iss. 3, pp. 407-415. 
Sonmez, M. and Yang, D. 2005, "Manchester United versus China: a counterfeiting and trademark match”, Managing Leisure, Vol. 10, pp. 1 - 18.

Steenhaut, S. and van Kenhove, P. 2006, “An Empirical Investigation of the Relationships among a Consumer’s Personal Values, Ethical Ideology and Ethical Beliefs:, Journal of Business Ethics, Vol. 64, pp. 137 - 155.

Swinyard, W.R., Rinne, H. and Kau, A.K. 1990, "The morality of software piracy: a cross-cultural analysis”, Journal of Business Ethics, Vol. 9, Iss. 8, pp. 655 - 664.

Tom, G., Garibaldi, B., Zeng, Y. and Pilcher, J. 1998, "Consumer Demand for Counterfeit Goods”, Psychology \& Marketing, Vol. 15, Iss. 5, pp. 405 - 421.

Trainer, T.P 2002, “The Fight Against Trademark Counterfeiting”, The China Business Review, pp. $21-24$.

Traphagan, M. and Griffith, A. 1998, "Software piracy and global competitiveness: report on global software piracy”, International Review of Law Computers \& Technology, Vol. 12, Iss. 3, pp. $431-451$.

Veblen, T. B. 1899, The Theory of the Leisure Class. Boston: Houghton Mifflin

Vinson, D. E., Munson, J.M. and Nakanishi, M. 1977, “An investigation of the Rokeach Value Survey for consumer research application”, in Perreault, W.E. (ed.), Advances in Consumer Research, Vol. 4. The Association for Consumer Research, Provo, UT. Pp. 247 - 252.

Wang, F., Zhang, H., Zang, H. and Ouyang, M. 2005, "Purchasing pirated software: an initial examination of Chinese consumers", Journal of Consumer Marketing, Vol. 22, Iss. 6, pp. $340-351$.

Wee, C. H., Tan, S. J. and Cheok, K. H. 1995, "Non-price determinants of intention to purchase counterfeit goods: An exploratory study", International Marketing Review, Vol. 12, Iss. 6, pp. $19-46$.

Wilke, R. Zaichkowsky, J. L. 1999, "Brand Imitation and Its Effects on Innovation, Competition and Brand Equity”, Business Horizons, Vol. 42, Iss. 6, pp. 9 - 19.

Wong, N. Y. and Ahuvia, A. C. 1998, "Personal Taste and Family Face: Luxury Consumption in Confucian and Western Societies”, Psychology \& Marketing, Vol. 15, Iss. 5, pp. $423-441$.

Yi, Y. 1990, "The indirect effects of advertisements designed to change product attribute beliefs”, Psychology \& Marketing, Vol. 7, pp. 47 - 64.

Yoo, B. and Lee, S. H. 2005, “Do Counterfeits Promote Genuine Products?”. Working Paper, Hofstra University, Hempstead, NY.

Zhou, L. and Hui, M. K. 2003, “Symbolic Value of Foreign Products in the People's Republic of China”, Journal of International Marketing, Vol. 11, Iss. 2, pp. 36 - 58. 
Zhou, N. and Belk, R. W. 2004, "Chinese Consumer Readings of Global and Local Advertising Appeals”, Journal of Advertising, Vol. 22, Iss. 3, pp. 63 - 76. 


\section{Tables}

Fig. 1: Research model of attitudes towards counterfeits of luxury brands

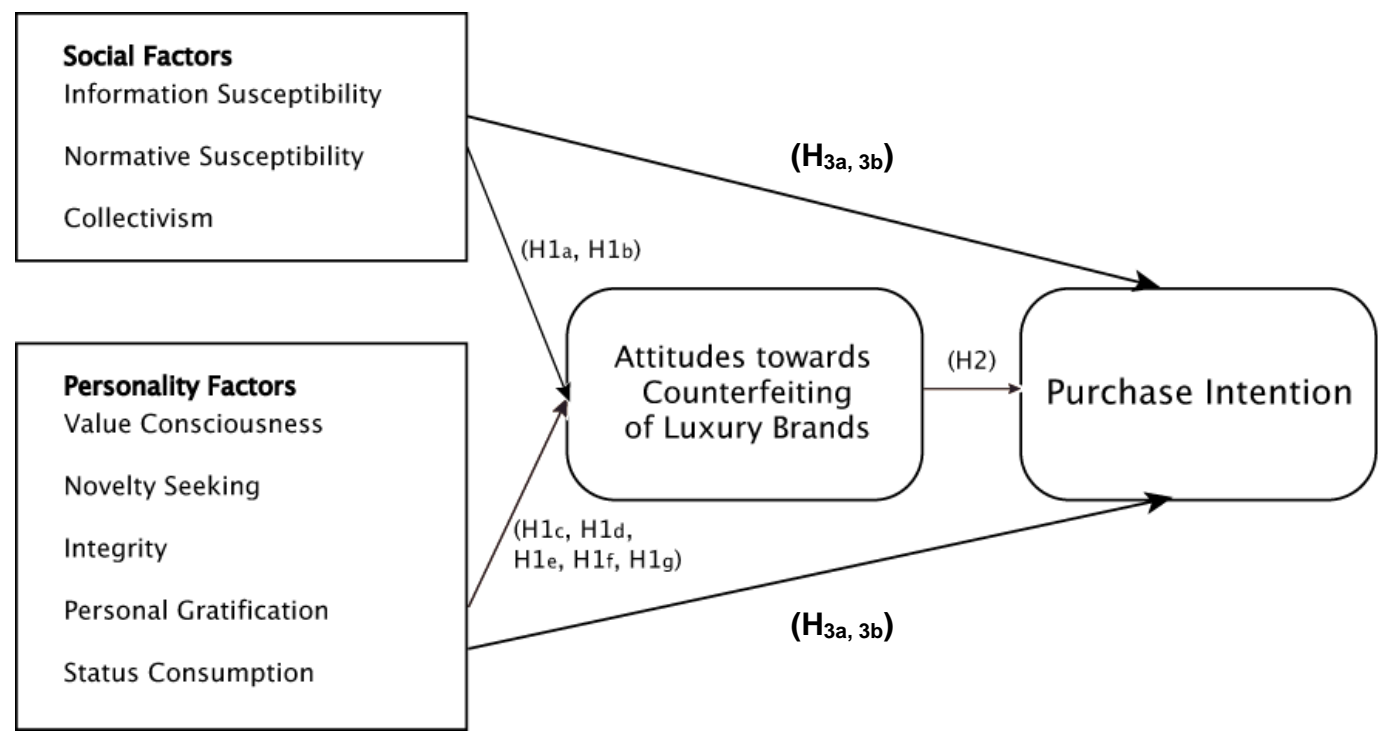


Table 1: Source and $\alpha$ coefficients of measurement scale items

\begin{tabular}{|l|c|c|c|}
\hline \multicolumn{1}{|c|}{ Scale Measure } & Source & Number of Items* & $\alpha$ Coefficient \\
\hline $\begin{array}{l}\text { Information } \\
\text { Susceptibility }\end{array}$ & Bearden et al. 1989 & 4 items & 0.733 \\
\hline $\begin{array}{l}\text { Normative } \\
\text { Susceptibility }\end{array}$ & Bearden et al. 1989 & 4 items & 0.721 \\
\hline Collectivism & Wang et al. 2005 & 4 items & 0.702 \\
\hline Value Consciousness & Lichtenstein et al. 1990 & 4 items & 0.747 \\
\hline Integrity & Rokeach 1973 & 4 items & 0.716 \\
\hline Personal Gratification & Vinson et al. 1977 & 5 items & 0.764 \\
\hline Novelty Seeking & Wee et al. 1995 & 4 items & 0.736 \\
\hline Status Consumption & Eastman et al. & 5 items & 0.708 \\
\hline $\begin{array}{l}\text { Attitudes towards } \\
\text { counterfeiting luxury } \\
\text { brands }\end{array}$ & Adapted by Wang et al. 2005 & 7 items & 0.661 \\
\hline Purchase Intention & Ang et al. 2001 & 4 items & 0.921 \\
\hline
\end{tabular}

* All scales rated on a 7 point Likert scale 
Table 2: Sample distribution between buyers and non-buyers of counterfeits of luxury brands

\begin{tabular}{|c|c|c|}
\hline Items & $\begin{array}{c}(25.2 \%) \text { Non Buyers } \\
N=51\end{array}$ & $\begin{array}{c}\text { (74.8 \%) Buyers } \\
\mathrm{N}=151\end{array}$ \\
\hline \multicolumn{3}{|l|}{ Gender } \\
\hline Female & $29.4 \%$ & $45.7 \%$ \\
\hline Male & $70.6 \%$ & $54.3 \%$ \\
\hline \multicolumn{3}{|l|}{ Age } \\
\hline Under 21 & $9.8 \%$ & $9.9 \%$ \\
\hline $21-35$ & $68.6 \%$ & $74.2 \%$ \\
\hline $36-45$ & $15.7 \%$ & $13.9 \%$ \\
\hline 46 and above & $5.9 \%$ & $2 \%$ \\
\hline \multicolumn{3}{|l|}{ Occupation } \\
\hline Business & $28 \%$ & $24.3 \%$ \\
\hline Self employed & $14 \%$ & $11.5 \%$ \\
\hline Executive & $10 \%$ & $10.8 \%$ \\
\hline Engineering & $10 \%$ & $9.5 \%$ \\
\hline Others & $38 \%$ & $44 \%$ \\
\hline \multicolumn{3}{|l|}{ Income } \\
\hline Under RMB50,000 & $56 \%$ & $57.5 \%$ \\
\hline RMB50,000 - RMB100,000 & $22 \%$ & $29.5 \%$ \\
\hline RMB100,001 - RMB150,000 & $14 \%$ & $3.4 \%$ \\
\hline RMB151,000 and above & $8 \%$ & $9.6 \%$ \\
\hline \multicolumn{3}{|l|}{ Education Level } \\
\hline Diploma or certificate & $30 \%$ & $24.5 \%$ \\
\hline Bachelor Degree & $60 \%$ & $56.5 \%$ \\
\hline Postgraduate Level & $6 \%$ & $10.2 \%$ \\
\hline Others & $4 \%$ & $8.8 \%$ \\
\hline
\end{tabular}


Table 3: Factor analysis on attitude towards counterfeits of luxury brands

\begin{tabular}{|l|c|c|}
\hline \multirow{2}{*}{ Items } & \multicolumn{1}{|c|}{ Factor Loadings } \\
\cline { 2 - 3 } & $\begin{array}{c}\text { F1 - Perceptions of } \\
\text { Counterfeits }\end{array}$ & $\begin{array}{c}\text { F2 - Social } \\
\text { Consequences }\end{array}$ \\
\hline $\begin{array}{l}\text { Counterfeits of luxury brands are as reliable } \\
\text { as the original version }\end{array}$ & 0.909 & \\
\hline $\begin{array}{l}\text { Counterfeits of luxury brands have similar } \\
\text { quality to the original version }\end{array}$ & 0.899 & \\
\hline $\begin{array}{l}\text { Counterfeits of luxury brands provided similar } \\
\text { functions as the original version }\end{array}$ & & \\
\hline $\begin{array}{l}\text { Buying counterfeits of luxury brands infringes } \\
\text { intellectual property }\end{array}$ & 0.861 & \\
\hline $\begin{array}{l}\text { Buying counterfeits of luxury brands will hurt } \\
\text { the luxury goods industry }\end{array}$ & & 0.890 \\
\hline $\begin{array}{l}\text { Buying counterfeits of luxury brands } \\
\text { damages interests and rights of } \\
\text { legitimate/original manufacturer }\end{array}$ & & \\
\hline $\begin{array}{l}\text { Purchasing counterfeits of luxury brands is } \\
\text { illegal }\end{array}$ & & \\
\hline \% of Variance & & \\
\hline Eigenvalue & & \\
\hline Cronbach Alpha & & \\
\hline Cronbach Alpha & & \\
\hline KMO & & \\
\hline Barlett's Test of Sphericity & 38.924 \\
\hline
\end{tabular}


Table 4: Stepwise regression results on factors influencing two dimensions of attitudes towards counterfeits of luxury brands

\begin{tabular}{lllllll}
\hline & B-Values & $\begin{array}{c}\text { Standard } \\
\text { Error }\end{array}$ & Beta & Adjusted R & t-value & Sig. \\
\hline $\begin{array}{l}\text { Perceptions of counterfeits } \\
\text { Status } \\
\text { Consumption }\end{array}$ & 0.910 & 0.164 & 0.601 & 0.283 & 5.534 & .000 \\
\hline $\begin{array}{l}\text { Novelty } \\
\text { Seeking }\end{array}$ & -0.441 & 0.158 & -0.283 & 0.316 & -2.790 & .006 \\
\hline $\begin{array}{l}\text { Normative } \\
\text { Susceptibility }\end{array}$ & 0.537 & 0.151 & 0.372 & 0.334 & 3.568 & .000 \\
\hline $\begin{array}{l}\text { Information } \\
\text { Susceptibility }\end{array}$ & -0.441 & 0.141 & -0.257 & 0.367 & -3.122 & .002 \\
\hline $\begin{array}{l}\text { Social Consequences } \\
\text { Integrity }\end{array}$ & -0.350 & 0.117 & -0.253 & 0.263 & -2.994 & .003 \\
\hline $\begin{array}{l}\text { Personal } \\
\text { Gratification }\end{array}$ & -0.222 & 0.096 & -0.187 & 0.335 & -2.317 & .022 \\
\hline $\begin{array}{l}\text { Status } \\
\text { Consumption }\end{array}$ & -0.187 & 0.068 & -0.188 & 0.359 & -2.724 & .007 \\
\hline $\begin{array}{l}\text { Value } \\
\text { Consciousness }\end{array}$ & -0.254 & 0.108 & -0.193 & 0.376 & -2.345 & .020 \\
\hline
\end{tabular}


Table 5: Stepwise regression on factors influencing purchase intention

\begin{tabular}{lcccccc}
\hline & B - Values & $\begin{array}{c}\text { Standard } \\
\text { Error }\end{array}$ & Beta & Adjusted $\mathbf{R}^{2}$ & t - value & Sig. \\
\hline $\begin{array}{l}\text { Status } \\
\text { Consumption }\end{array}$ & 0.623 & 0.120 & 0.448 & 0.325 & 5.171 & 0.000 \\
\hline $\begin{array}{l}\text { Integrity } \\
\text { Value }\end{array}$ & -0.498 & 0.163 & -0.242 & 0.339 & -3.061 & 0.003 \\
\hline $\begin{array}{l}\text { Consciousness } \\
\text { Surmative }\end{array}$ & 0.381 & 0.148 & 0.203 & 0.359 & 2.268 & 0.011 \\
\hline $\begin{array}{l}\text { Information } \\
\text { Susceptibility }\end{array}$ & 0.448 & 0.133 & 0.341 & 0.371 & 3.365 & 0.001 \\
\hline
\end{tabular}


Table 6: Buyers and non-buyers attitudes towards counterfeits of luxury brands

\begin{tabular}{|c|c|c|c|}
\hline Measures & Non-Buyers & Buyers & t-value \\
\hline \multicolumn{4}{|l|}{ Factor 1 - Perceptions of Counterfeits } \\
\hline $\begin{array}{l}\text { Counterfeits of luxury brands have similar quality to the } \\
\text { original version }\end{array}$ & 3.86 & 4.07 & $-.603^{\star \star}$ \\
\hline $\begin{array}{l}\text { Counterfeits of luxury brands provide similar functions as } \\
\text { the original version }\end{array}$ & 4.27 & 4.46 & $-.622^{\star \star}$ \\
\hline $\begin{array}{l}\text { Counterfeits of luxury brands are as reliable as the original } \\
\text { version }\end{array}$ & 3.80 & 3.83 & $-.064^{\star \star}$ \\
\hline \multicolumn{4}{|l|}{ Factor 2 - Social consequences } \\
\hline $\begin{array}{l}\text { Buying counterfeits of luxury brands infringes intellectual } \\
\text { property }\end{array}$ & 2.04 & 2.69 & -3.179 \\
\hline $\begin{array}{l}\text { Buying counterfeits of luxury brands damages interests } \\
\text { and rights of legitimate/original manufacturer }\end{array}$ & 2.10 & 2.62 & -2.443 \\
\hline $\begin{array}{l}\text { Buying counterfeits of luxury brands will hurt the luxury } \\
\text { goods industry }\end{array}$ & 2.18 & 2.71 & -2.323 \\
\hline Purchasing counterfeits of luxury brands is illegal & 2.45 & 2.93 & -1.722 \\
\hline ** $p \leq 0.005$ & & & \\
\hline
\end{tabular}

